\title{
Application of Firefly Algorithm in Voltage Stability Environment Incorporating Circuit Element Model of SSSC with Variable Susceptance Model of SVC
}

\author{
Luke Jebaraj, ${ }^{1}$ Charles Christober Asir Rajan, ${ }^{2}$ and Kumar Sriram ${ }^{1}$ \\ ${ }^{1}$ Department of Electrical and Electronics Engineering, St.Anne's College of Engineering and Technology, Panruti, \\ Tamil Nadu 607 110, India \\ ${ }^{2}$ Department of Electrical and Electronics Engineering, Pondicherry Engineering College, Puducherry 605 014, India \\ Correspondence should be addressed to Luke Jebaraj; jeba_meps@yahoo.co.in
}

Received 31 January 2014; Revised 2 April 2014; Accepted 3 April 2014; Published 24 April 2014

Academic Editor: José R. C. Piqueira

Copyright (C) 2014 Luke Jebaraj et al. This is an open access article distributed under the Creative Commons Attribution License, which permits unrestricted use, distribution, and reproduction in any medium, provided the original work is properly cited.

\begin{abstract}
This paper proposes an application of firefly algorithm (FA) based extended voltage stability margin and minimization of active (or) real power loss incorporating Series-Shunt flexible AC transmission system (FACTS) controller named as static synchronous series compensator (SSSC) combined with static var compensator (SVC). A circuit model of SSSC and variable susceptance model of SVC are utilized to control the line power flows and bus voltage magnitudes, respectively, for real power loss minimization and voltage stability limit improvement. The line quality proximity index (LQP) is used to assess the voltage stability of a power system. The values of voltage profile improvement, real power loss minimization, and the location and size of FACTS devices were optimized by FA. The results are obtained from the IEEE 14- and 30-bus test case systems under different operating conditions and compared with other leading evolutionary techniques such as shuffled frog leaping algorithm (SFLA), differential evolution (DE) and particle swarm optimization (PSO).
\end{abstract}

\section{Introduction}

Voltage stability is concerned with the ability of a power system to maintain acceptable voltage at all buses in the system under normal conditions and after being subjected to a disturbance [1]. The recent day power systems are undergoing numerous changes and becoming more complex from the standpoints of operation, control, and stability maintenance when they meet ever-increasing load demand [2]. A system enters a state of voltage instability when a disturbance, increase in load demand, or change in system condition causes a progressive and uncontrollable decline in voltage. The main factor causing voltage instability is the inability of the power system to meet the demand for reactive power $[3,4]$. The authors $[5,6]$ discuss methods to assess voltage stability of a power system to find possible ways to improve the voltage stability.

Abnormal voltages and voltage collapse pose a primary threat to power system stability, security, and reliability.
Moreover, with the fast development of restructuring, the problem of voltage stability has become a major concern in deregulated power systems. To maintain security of such systems, it is desirable to plan suitable measures to improve power system security and increase voltage stability margins [7]. Voltage instability is one of the phenomena which have resulted in major blackouts. Recently, several network blackouts have been related to voltage collapse [8]. The only way to counteract this problem is by reducing the reactive power load in the system or by adding new reactive power generation systems in the weakest points of the system, thereby, increasing the voltage at those points.

The flexible AC transmission system (FACTS) controllers are capable of supplying or absorbing reactive power at faster rates [9]. The introduction of FACTS controllers are increasingly used to provide voltage and power flow controls [10]. Insertion of FACTS devices is found to be highly effective in preventing voltage instability and minimize the active or real power loss on transmission lines $[11,12]$. Series and shunt 
compensating devices are used to enhance the static voltage stability margin and reduce the real power loss appreciably $[13,14]$.

The generalized power injection model of SSSC needs modification of the Jacobian matrix and makes quite complex in coding. In the SSSC control parameters, voltage magnitude and angle of the series converters are presented as independent variables and their values are found through the traditional load flow iterative process [15]. In this case, the size of the Jacobian matrix increases to incorporate the additional independent variables. The new model of the SSSC changes only the bus admittance matrix and consequently reduces the coding of load flow problem incorporating SSSC simple. The SSSC control parameters, voltage magnitude and angle of the series converters, are presented as independent variables and their values are found through the traditional load flow iterative process. In this case, the size of the Jacobian matrix increases to incorporate the additional independent variables. Hence, a simple and easy way to implement SSSC model based on the circuit elements is used in this work [16].

Voltage stability assessment with appropriate representations of FACTS devices is investigated and compared under base case of study [17-19]. One of the shortcomings of those methods only considered the normal state of the system [20]. The author [21] presented the different computational techniques for voltage stability assessment and control. The author [22] focused on the contingency ranking obtained with respect to overloads in large power systems. Abdelaziz et al. [23] proposed the process of contingency ranking through fuzzy logic approach. However, voltage collapses are mostly initiated by a disturbance like line outages. Voltage stability limit improvement needs to be addressed during network contingencies. So, to locate FACTS devices, consideration of contingency conditions is more important than consideration of normal state of system and some approaches are proposed to locate FACTS devices with considerations of contingencies too $[24,25]$.

Line stability indices provide important information about the proximity of the system to voltage instability and can be used to identify the weakest bus as well as the critical line with respect to the bus of the system [26]. Different types of line stability indices are proposed to evaluate the proximity of the system to voltage instability [27, 28]. The line quality proximity index is used in this work for stability assessment [29, 30]. From the family of bioluminescence inspired computation, FA is used to solve the problem of real power loss minimization and voltage stability maximization of the system. In the firefly algorithm, the objective function of a given optimization problem is based on differences in light intensity. It helps the fireflies to move towards brighter and more attractive locations in order to obtain optimal solutions. All fireflies are characterized by their light intensity associated with the objective function [31-33].

Because of higher cost of the FACTS devices, the installation is not recommended to all possible line outages. Hence, line outage contingency screening and ranking were carried out to identify the most critical line during which outage FACTS controllers can be positioned and system can be operated under stable condition [34-36]. The prime objective

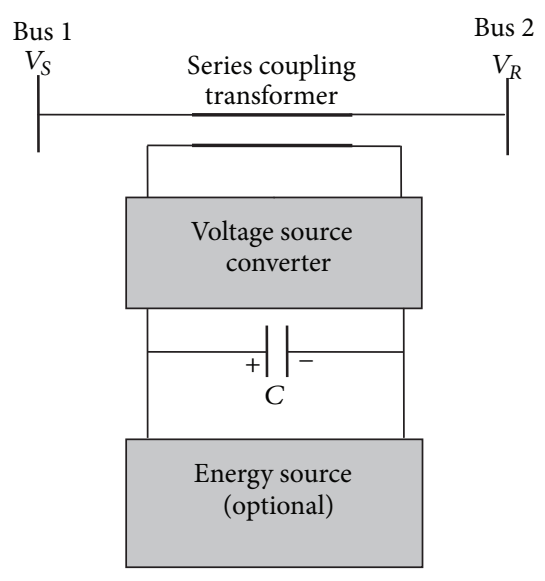

FIGURE 1: SSSC configuration.

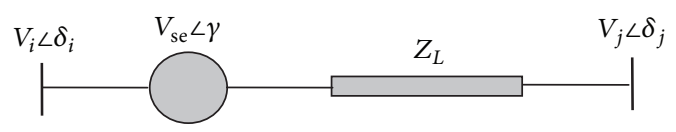

FIgURE 2: Circuit element model of SSSC.

of this work is to obtain the results from standard IEEE 14- and 30-bus test cases through FA incorporating circuit element model of SSSC combined with variable susceptance model of SVC and to compare the results of these seriesshunt FACTS controllers with other important evolutionary techniques such as SFLA, DE, and PSO under normal, critical loading and single-line outage conditions.

\section{Static Model of FACTS Devices}

2.1. Circuit Element Model of SSSC. The SSSC can be operated without an external energy source as reactive power source and is fully controllable and independent of transmission line current for the purpose of increasing or decreasing the overall reactive voltage drop across the transmission line and thereby controlling the electric power flow. The widely used power injection model of SSSC requires modification of the Jacobian matrix and makes the Newton-Raphson load flow (NRLF) coding more complex. A new circuit elements based model of SSSC is utilized to control the line power flows and bus voltage magnitudes for voltage stability limit improvement. The new model of the SSSC changes only the bus admittance matrix and consequently reduces the coding of load flow problem incorporating SSSC simple. This converter performs the main function of injecting a controllable series voltage. The basic configuration of SSSC is depicted in Figure 1. The circuit element model of SSSC is also shown in Figure 2.

The real and reactive powers exchanged with the line by the series voltage inserted by SSSC are modeled as a negative resistance and reactance connected in parallel. The negative resistance represents injection of real power and the reactance may be either capacitive or inductive depending on whether reactive power is delivered or absorbed. 
The complex power exchanged by the series converter with the line is expressed as

$$
S_{e}=V_{\mathrm{se}} I
$$

where $V_{\text {se }}$ is the complex voltage injected by the converter and $I$ the current through the line given by

$$
I=\frac{V_{i} \angle \delta_{i}+V_{\mathrm{se}} \angle \gamma-V_{j} \angle \delta_{j}}{Z_{L}} .
$$

The active and reactive powers exchanged with the line are modeled as resistance and reactance associated as represented by

$$
\begin{gathered}
R=\frac{V_{\mathrm{se}}^{2}}{P_{\mathrm{se}}}, \\
X=\frac{V_{\mathrm{se}}^{2}}{Q_{\mathrm{se}}} .
\end{gathered}
$$

The elements $R$ and $X$ can be calculated by directly using the following equations:

$$
\begin{gathered}
R=\frac{V_{\mathrm{se}} Z_{L}}{V_{i} \sin \left(\delta_{i}-\delta_{j}-\gamma\right)+V_{j} \sin \gamma}, \\
X=\frac{V_{\mathrm{se}} Z_{L}}{V_{i} \cos \left(\delta_{i}-\delta_{j}-\gamma\right)-V_{j} \cos \gamma+V_{\mathrm{se}}} .
\end{gathered}
$$

The resistance $R$ and the reactance $X$ representing the effect of series voltage are transformed into their equivalent series combination. This makes the line simple with only seriesconnected elements of the line $\left(Z_{L}\right)$ and the $R_{\mathrm{SSSC}}$ and $X_{\mathrm{SSSC}}$ denoting the resistance and reactance of SSSC:

$$
\begin{aligned}
& R_{\mathrm{SSSC}}=\frac{R X^{2}}{R^{2}+X^{2}}, \\
& X_{\mathrm{SSSC}}=\frac{X R^{2}}{R^{2}+X^{2}} .
\end{aligned}
$$

2.2. Variable Susceptance Model of SVC. A variable susceptance $B_{\mathrm{SVC}}$ represents the fundamental frequency equivalent susceptance of all shunt modules making up the SVC. This model is an improved version of SVC models. Figure 3 shows the variable susceptance model of SVC which is used to derive its nonlinear power equations and the linearised equations required by Newton's load flow method.

In general, the transfer admittance equation for the variable shunt compensator is

$$
I_{\mathrm{SVC}}=j B_{\mathrm{SVC}} V_{j}
$$

And the reactive power of SVC is

$$
Q_{\mathrm{SVC}}=-V_{j}^{2} B_{\mathrm{SVC}} .
$$

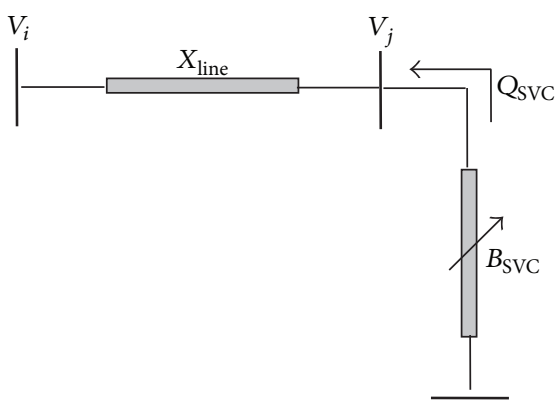

FIgURE 3: Variable susceptance model of SVC.

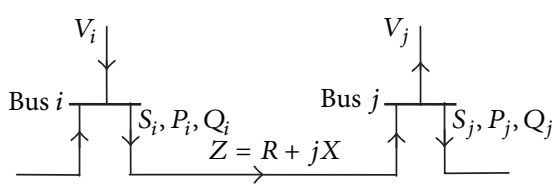

FIGURE 4: Single-line concept of power transmission.

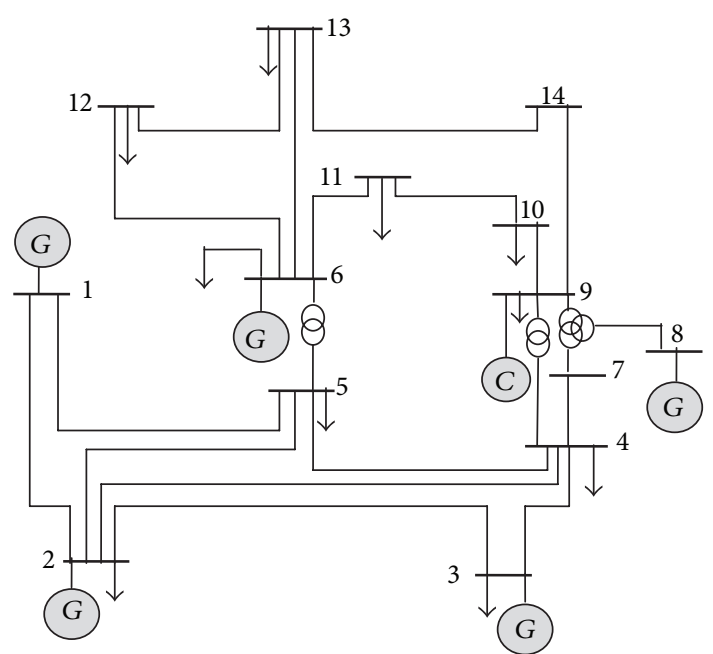

(a) 14-bus system

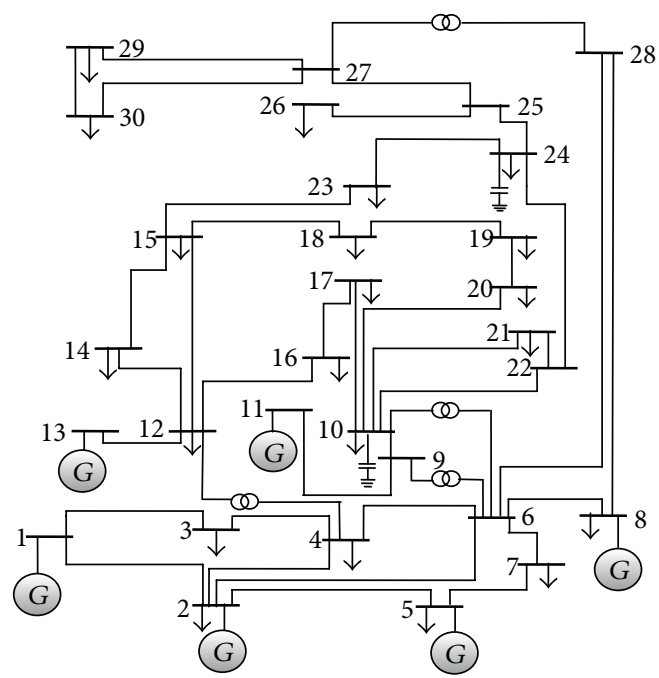

(b) 30-bus system

FIgure 5: One-line diagram of IEEE test system. 


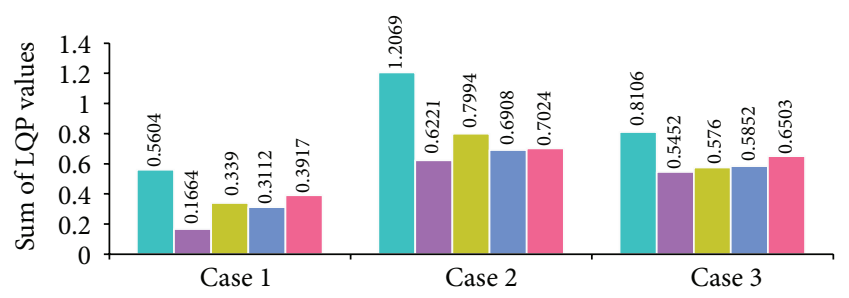

(a) For 14-bus system

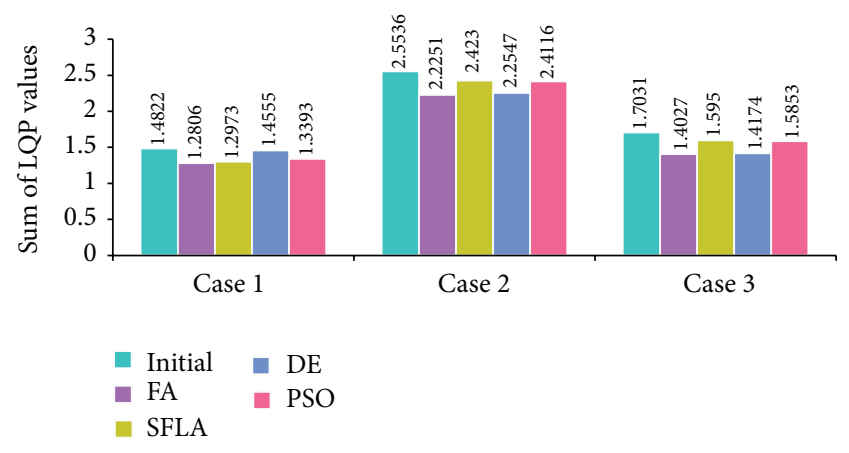

(b) For 30-bus system

FIGURE 6: Sum of LQP index values comparison.

In SVC susceptance model, the total susceptance $B_{\mathrm{SVC}}$ is taken to be the state variable; therefore the linearised equation of the SVC is given by

$$
\left[\begin{array}{c}
\Delta P_{j} \\
\Delta Q_{j}
\end{array}\right]=\left[\begin{array}{cc}
0 & 0 \\
0 & \theta_{j}
\end{array}\right]\left[\begin{array}{c}
\Delta \theta_{j} \\
\frac{\Delta B_{\mathrm{svc}}}{B_{\mathrm{svc}}}
\end{array}\right]
$$

where $\Delta P_{j}, \Delta Q_{j}$, and $\Delta \theta_{j}$ are the change in real, reactive power, and voltage angle at $j$ th bus.

At the end of iteration $i$, the variable shunt susceptance $B_{\mathrm{SVC}}$ is updated according to

$$
B_{\mathrm{SVC}}^{(i)}=B_{\mathrm{SVC}}^{(i-1)}+\left(\frac{\Delta B_{\mathrm{SVC}}}{B_{\mathrm{SVC}}}\right)^{(i)} B_{\mathrm{SVC}}^{(i-1)} .
$$

This changing susceptance value represents the total SVC susceptance which is necessary to maintain the nodal voltage magnitude at the specified value (1.0 p.u. in this paper).

\section{Line Quality Proximity Index}

Voltage stability can be assessed in a system by calculating the line based voltage stability index. The LQP index based on a power transmission concept is used in this paper. The value of line index shows the voltage stability of the system. The value close to unity indicates that the respective line is close to its stability limit and value much close to zero indicates light load in the line. The formulation begins with the power equation in a power system. Figure 4 illustrates a single line of a power transmission concept.
The power equation can be derived as

$$
P_{i}=\sqrt{\frac{V_{i}^{2}}{X}\left(Q_{i}-Q_{j}\right)-Q_{i}^{2}} .
$$

The line stability factor isobtained by setting the discriminant of the reactive power roots at bus 1 to be greater than or equal to zero, thus defining the line stability factor, LQP, as

$$
\mathrm{LQP}=4\left(\frac{X}{V_{i}^{2}}\right)\left(\frac{X}{V_{i}^{2}} P_{i}^{2}+Q_{j}\right) .
$$

\section{Problem Formulation}

The objective function of this work is to find the optimal rating and location of FACTS devices combination which minimizes the real power loss, minimizes voltage deviation, and maximizes the voltage stability limit. Hence, the objective function can be expressed as

$$
F=\min \left\{P_{L}+w \mathrm{VD}+(1-w) \mathrm{LQP}\right\}
$$

where $w$ is the weighing factor for voltage deviation and is set to 10 .

4.1. Minimization of Real Power Loss $\left(P_{L}\right)$. The total real power of the system can be calculated as follows:

$$
P_{\text {loss }}=\sum_{k=1}^{N_{L}} G_{k}\left[V_{i}^{2}+V_{j}^{2}-2\left|V_{i}\right|\left|V_{j}\right| \cos \left(\delta_{i}-\delta_{j}\right)\right] \text {, }
$$

where $N_{L}$ is the total number of lines in the system; $G_{k}$ is the conductance of the line " $k$ "; $V_{i}$ and $V_{j}$ are the magnitudes of the sending end and receiving end voltages of the line; and $\delta_{i}$ and $\delta_{j}$ are angles of the end voltages.

4.2. Minimization of Load Bus Voltage Deviation (VD). Bus voltage magnitude should be maintained within the allowable range to ensure quality service. Voltage profile is improved by minimizing the deviation of the load bus voltage from the reference value (it is taken as 1.0 p.u. in this work):

$$
\mathrm{VD}=\sum_{k=1}^{N_{\mathrm{PQ}}}\left|V_{I}-V_{\mathrm{ref}}\right|
$$

where $V_{i}$ is the voltage at $i$ th bus and $V_{\text {ref }}$ is the reference voltage.

4.3. Minimization of Line Quality Proximity Index (LQP). Voltage stability limit of a power system is increased by minimizing voltage stability index value. The indicator takes values between 0 (no load) and 1 (full load). The line based stability index (LQP) is given as

$$
\mathrm{LQP}=\sum_{j=1}^{N_{L}} \mathrm{LQP}_{j} .
$$




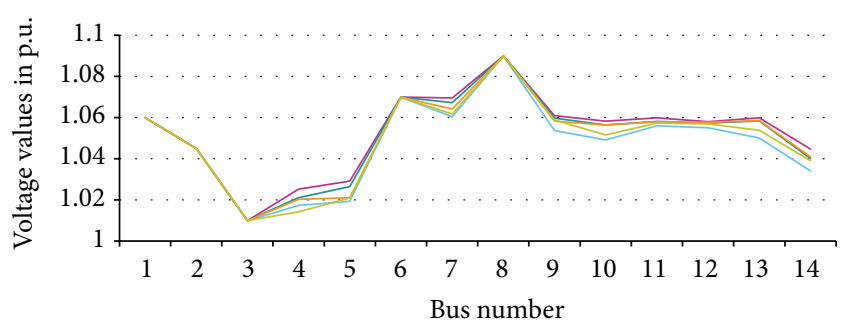

(i) Case 1

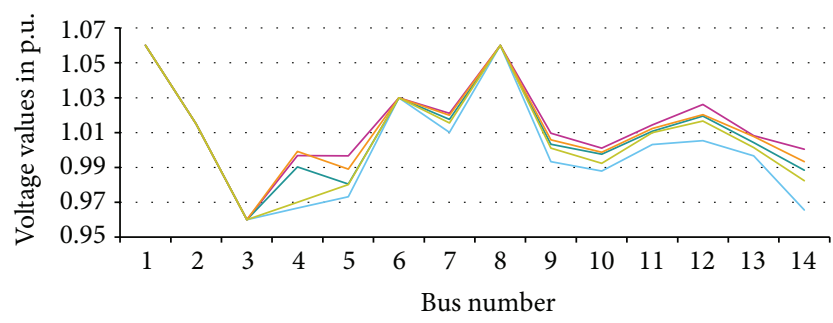

(ii) Case 2

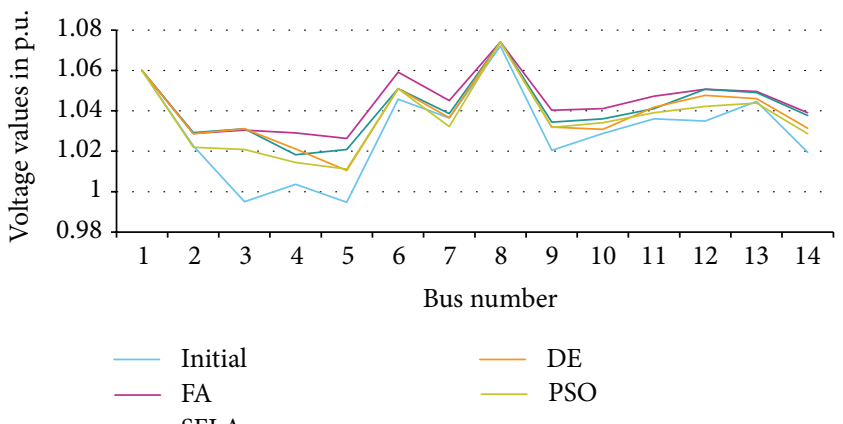

(iii) Case 3

(a)

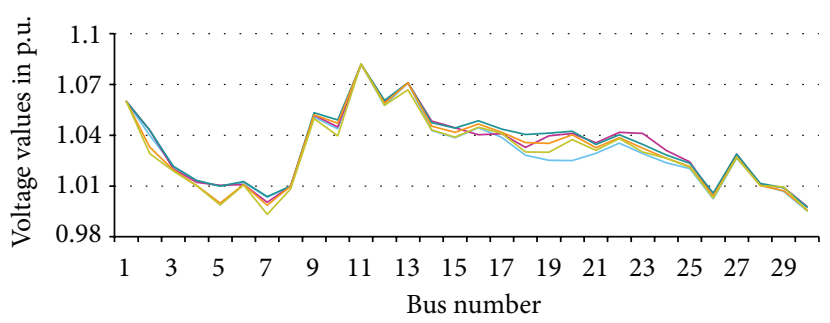

(i) Case 1

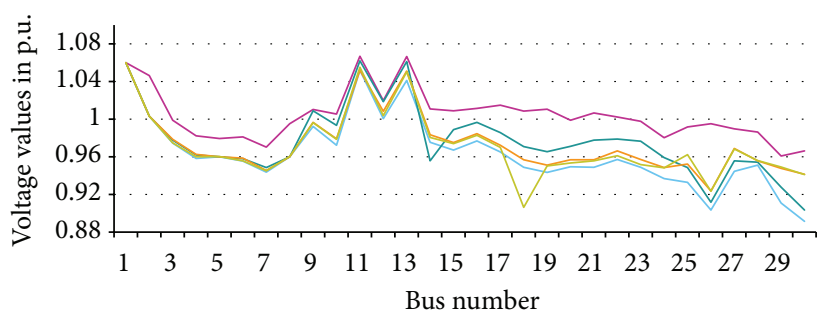

(ii) Case 2

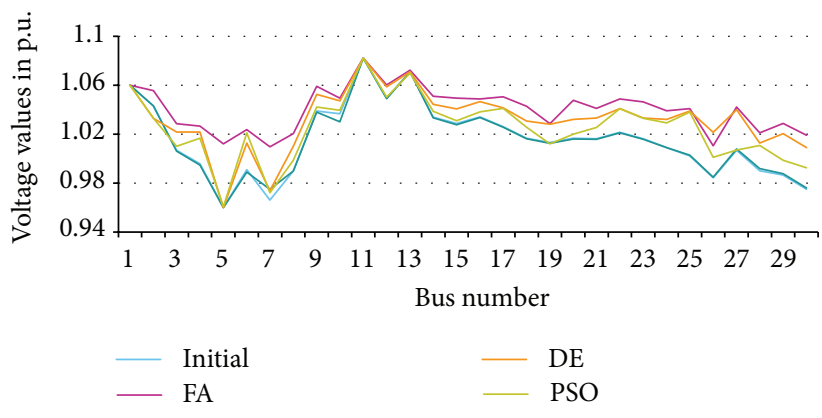

(iii) Case 3

(b)

FiguRE 7: (a) Voltage profile values comparison for 14-bus system. (b) Voltage profile values comparison for 30-bus system.

4.4. Constraints. The minimization problem is subject to the following equality and inequality constraints.

\subsubsection{Equality Constraints}

Load Flow Constraints. Consider

$$
\begin{gathered}
P_{\mathrm{Gi}}-P_{\mathrm{Di}}-\sum_{j=1}^{N_{B}} V_{i} V_{j} Y_{i j} \cos \left(\delta_{i j}+\gamma_{j}-\gamma_{i}\right)=0, \\
Q_{\mathrm{Gi}}-Q_{\mathrm{Di}}-\sum_{j=1}^{N_{B}} V_{i} V_{j} Y_{i j} \sin \left(\delta_{i j}+\gamma_{j}-\gamma_{i}\right)=0,
\end{gathered}
$$

where $P_{\mathrm{Gi}}$ and $Q_{\mathrm{Gi}}$ are the active and reactive powers of $i$ th generator and $P_{\mathrm{Di}}$ and $Q_{\mathrm{Di}}$ are the active and reactive powers of $i$ th load bus.

\subsubsection{Inequality Constraints}

Reactive Power Generation Limit of SVCs. By choosing smallsized compensator, capital cost involved can be minimum.
The size limit of SVC has been taken from minimum of 5 MVAR to maximum of 20 MVAR:

$$
Q_{\mathrm{SVCi}}^{\min } \leq Q_{\mathrm{SVCi}} \leq Q_{\mathrm{SVCi}}^{\max } ; \quad i \in N_{\mathrm{SVC}}
$$

where $Q_{\mathrm{SVCi}}^{\min }$ and $Q_{\mathrm{SVCi}}^{\max }$ are the minimum and maximum VAR injection limits of $i$ th shunt capacitor.

Voltage Constraints. The acceptable voltage limits in all load buses are taken from 0.95 p.u. to 1.05 p.u. to avoid voltage instability:

$$
V_{i}^{\min } \leq V_{i} \leq V_{i}^{\max } ; \quad i \in N_{B}
$$

where $V_{i}^{\min }$ and $V_{i}^{\max }$ are the minimum and maximum value voltage of bus " $i$ ".

\section{Transmission Line Flow Limit. Consider}

$$
S_{i} \leq S_{i}^{\max } ; \quad i \in N_{l},
$$

where $S_{i}$ is the apparent power flow of $i$ th branch and $S_{i}^{\max }$ is the maximum apparent power flow limit of $i$ th branch. 


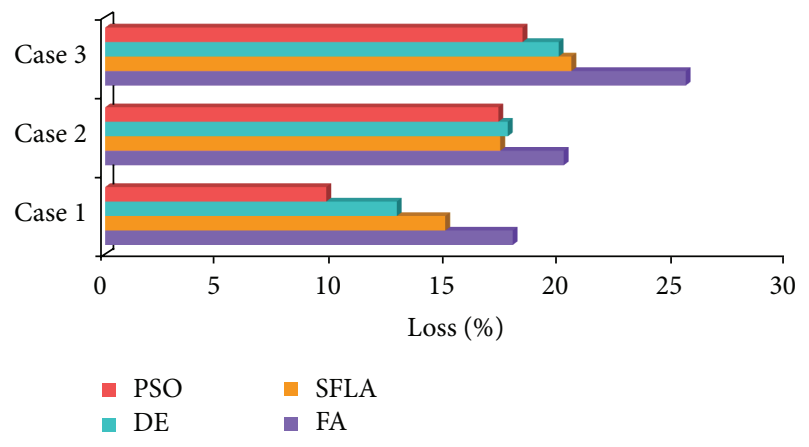

(a) For 14-bus system

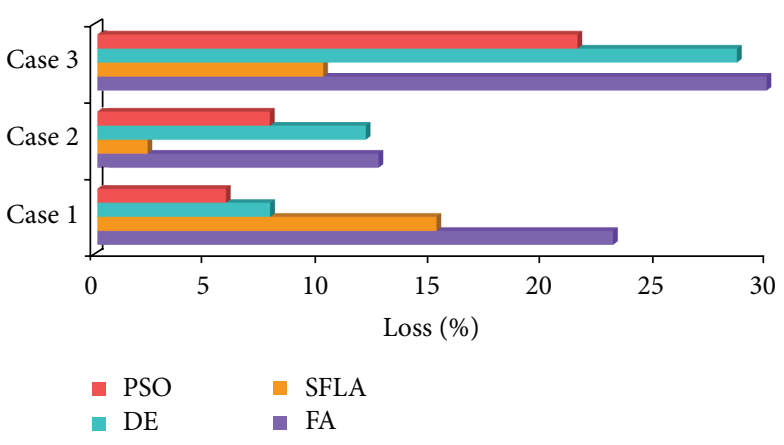

(b) For 30-bus system

FIgURE 8: Percentage of real power loss reduction under all cases.

TABLE 1: Optimal values of FA parameters.

\begin{tabular}{lc}
\hline Parameters & Optimal Values \\
\hline Number of fireflies & 30 \\
$\beta_{0}$ & 0.1 \\
$\gamma$ & 0.2 \\
$\alpha$ & 0.25 \\
$m$ & 4.0 \\
$d$ & 2.0 \\
Maximum iterations & 100 \\
\hline
\end{tabular}

\section{Firefly Algorithm}

5.1. Overview. The firefly algorithm (FA) is a metaheuristic, nature-inspired, optimization algorithm which is based on the social (flashing) behavior of fireflies, or lighting bugs, in the summer sky in the tropical temperature regions. It was developed by Dr. Xin-She Yang at Cambridge University in 2007, and it is based on the swarm behavior such as fish, insects, or bird schooling in nature. In particular, although the firefly algorithm has many similarities with other algorithms which are based on the so-called swarm intelligence, such as the famous particle swarm optimization (PSO), artificial bee colony optimization (ABC), and bacterial foraging algorithms (BFA), it is indeed much simpler in both concept and implementation. Furthermore, according to recent bibliography, the algorithm is very efficient and can outperform other conventional algorithms, such as genetic algorithms, for solving many optimization problems, a fact that has been justified in a recent research, where the statistical performance of the firefly algorithm was measured against other well-known optimization algorithms using various standard stochastic test functions. Its main advantage is the fact that it uses mainly real random numbers and it is based on the global communication among the swarming particles (i.e., the fireflies), and as a result, it seems more effective in multiobjective optimization such as the economic emissions load dispatch problem in our case.

The firefly algorithm has three particular idealized rules which are based on some of the major flashing characteristics of real fireflies. These rules are the following. (i) All fireflies are unisex, and they will move towards more attractive and brighter ones regardless their sex.

(ii) The degree of attractiveness of a firefly is proportional to its brightness which decreases as the distance from the other firefly increases due to the fact that the air absorbs light. If there is no brighter or more attractive firefly than a particular one, it will then move randomly.

(iii) The brightness or light intensity of a firefly is determined by the value of the objective function of a given problem. For maximization problems, the light intensity is proportional to the value of the objective function.

\subsection{Implementation}

5.2.1. Attractiveness. In the firefly algorithm, the form of attractiveness functions of a firefly is the following monotonically decreasing function:

$$
\beta(r)=\beta_{0} * \exp \left(-\gamma r^{m}\right), \quad \text { with } m \geq 1,
$$

where $r$ is the distance between any two fireflies, $\beta_{0}$ is the initial attractiveness at $r=0$, and $\gamma$ is an absorption coefficient which controls the decrease of the light intensity.

5.2.2. Distance. The distance between any two fireflies $i$ and $j$, at positions $x_{i}$ and $x_{j}$, respectively, can be defined as a Cartesian or Euclidean distance as follows:

$$
r_{i j}=\left\|x_{i}-x_{j}\right\|=\sqrt{\sum_{k=1}^{d}\left(x_{i, k}-x_{j, k}\right)^{2}},
$$

where $x_{i, k}$ is the $k$ th component of the spatial coordinate $x_{i}$ of the $i$ th firefly and $d$ is the number of dimensions we have, for $d=2$; we have

$$
r_{i j}=\sqrt{\left(x_{i}-x_{j}\right)^{2}+\left(y_{i}-y_{j}\right)^{2}} .
$$

However, the calculation of distance $r$ can also be defined using other distance metrics, based on the nature of the problem, such as Manhattan distance. 
TABLE 2: Voltage stability index values of most stressed lines.

(a) For 14-bus system

\begin{tabular}{lcccccc}
\hline \multirow{2}{*}{ Cases } & Line number & Preinsertion of FACTS & \multicolumn{3}{c}{ Postinsertion of FACTS } \\
& & & FA & SFLA & DE & 0.0807 \\
& 14 & 0.1122 & 0.0714 & 0.0818 & 0.0807 \\
Case 1 & 20 & 0.0776 & 0.0582 & 0.0537 & 0.0544 & 0.0617 \\
& 1 & 0.0688 & 0.0447 & 0.0511 & 0.0491 & 0.0519 \\
& 17 & 0.0593 & 0.0310 & 0.0388 & 0.0408 & 0.0503 \\
& 9 & 0.0515 & 0.0291 & 0.0346 & 0.0307 & 0.0401 \\
\hline \multirow{3}{*}{ Case 2 } & 10 & 0.2580 & 0.1106 & 0.1722 & 0.1651 & 0.1995 \\
& 14 & 0.1815 & 0.0994 & 0.0991 & 0.1012 & 0.1244 \\
& 20 & 0.1494 & 0.0912 & 0.0941 & 0.1109 & 0.1286 \\
& 9 & 0.1393 & 0.0833 & 0.0994 & 0.1081 & 0.1120 \\
Case 3 & 1 & 0.0799 & 0.0517 & 0.0604 & 0.0597 & 0.0661 \\
& 10 & 0.1904 & 0.1014 & 0.0941 & 0.1057 & 0.1129 \\
& 15 & 0.1160 & 0.0809 & 0.0802 & 0.0914 & 0.0956 \\
& 6 & 0.0914 & 0.0529 & 0.0317 & 0.0441 & 0.0582 \\
& 4 & 0.0793 & 0.0447 & 0.0406 & 0.0533 & 0.0551 \\
& 9 & 0.0648 & 0.0361 & 0.0304 & 0.0369 & 0.0408 \\
\hline
\end{tabular}

(b) For 30-bus system

\begin{tabular}{|c|c|c|c|c|c|c|}
\hline \multirow{2}{*}{ Cases } & \multirow{2}{*}{ Line number } & \multirow{2}{*}{ Preinsertion of FACTS } & \multicolumn{4}{|c|}{ Postinsertion of FACTS } \\
\hline & & & FA & SFLA & $\mathrm{DE}$ & PSO \\
\hline \multirow{5}{*}{ Case 1} & 12 & 0.3691 & 0.3664 & 0.3687 & 0.3700 & 0.3683 \\
\hline & 5 & 0.1284 & 0.0695 & 0.1264 & 0.0987 & 0.1282 \\
\hline & 13 & 0.1226 & 0.0722 & 0.0114 & 0.1169 & 0.1095 \\
\hline & 15 & 0.0749 & 0.0713 & 0.0748 & 0.0752 & 0.0749 \\
\hline & 14 & 0.0678 & 0.0667 & 0.0674 & 0.0676 & 0.0672 \\
\hline \multirow{5}{*}{ Case 2} & 12 & 0.3899 & 0.3861 & 0.3877 & 0.3874 & 0.3881 \\
\hline & 5 & 0.3596 & 0.0884 & 0.3310 & 0.0793 & 0.3312 \\
\hline & 13 & 0.2549 & 0.2115 & 0.2355 & 0.2351 & 0.2390 \\
\hline & 16 & 0.1687 & 0.1241 & 0.1735 & 0.1767 & 0.1610 \\
\hline & 15 & 0.1255 & 0.1167 & 0.1245 & 0.1244 & 0.1249 \\
\hline \multirow{5}{*}{ Case 3} & 12 & 0.3851 & 0.3688 & 0.3864 & 0.3686 & 0.3793 \\
\hline & 13 & 0.1732 & 0.1159 & 0.1766 & 0.1152 & 0.1711 \\
\hline & 16 & 0.0836 & 0.0445 & 0.0855 & 0.0475 & 0.0833 \\
\hline & 1 & 0.0786 & 0.0540 & 0.0810 & 0.0568 & 0.0694 \\
\hline & 15 & 0.0775 & 0.0741 & 0.0776 & 0.0749 & 0.0771 \\
\hline
\end{tabular}

5.2.3. Movement. The movement of a firefly $i$ which is attracted by a more attractive (i.e., brighter) firefly $j$ is given by the following equation:

$$
x_{i}=x_{i}+\beta_{0} * \exp \left(-\gamma r_{i j}^{2}\right) *\left(x_{i}-x_{j}\right)+\alpha *\left(\operatorname{rand}-\frac{1}{2}\right),
$$

where the first term is the current position of a firefly, the second term is used for considering a firefly's attractiveness to light intensity seen by adjacent fireflies, and the third term issued for the random movement of a firefly in case there are no any brighter ones. The coefficient $\alpha$ is a randomization parameter determined by the problem of interest, while rand is a random number generator uniformly distributed in the space $(0,1)$. As we will see in this implementation of the algorithm, we use $\beta_{0}=0.1, \alpha \in[0,1]$, and the attractiveness or absorption coefficient $\gamma=0.2$, which guarantees a quick convergence of the algorithm to the optimal solution. The optimal values of firefly parameters are in Table 1.

\section{Results and Discussion}

The proposed work is coded in MATLAB 7.6 platform using 2.8 GHz Intel Core 2 Duo processor based PC. The method is tested in the IEEE 14- and 30-bus test systems shown in Figure 5. The line data and bus data are taken from the standard power system test case archive. The 14-bus system has 5 generator buses, 9 load buses, and 20 transmission lines. 
TABLE 3: Contingency ranking.

\begin{tabular}{lcccc}
\hline Rank & Line number & 14-bus system & \multicolumn{2}{c}{ 30-bus system } \\
\hline 1 & 1 & LQP values & Line number & 5 \\
2 & 3 & 0.5795 & 9 & 0.9495 \\
3 & 10 & 0.3826 & 2 & 0.6050 \\
4 & 2 & 0.3449 & 4 & 0.4993 \\
5 & 15 & 0.3157 & 7 & 0.4968 \\
\hline
\end{tabular}

TABLE 4: Average load bus voltage values in p.u.

(a) For 14-bus system

\begin{tabular}{lccccc}
\hline \multirow{2}{*}{ Cases } & \multirow{2}{*}{ Preinsertion of FACTS } & \multicolumn{3}{c}{ Postinsertion of FACTS } \\
& & FA & SFLA & DE & PSO \\
\hline Case 1 & 1.0438 & 1.0517 & 1.0494 & 1.0483 & 1.0460 \\
Case 2 & 0.9890 & 1.0082 & 1.0013 & 1.0051 & 0.9966 \\
Case 3 & 1.0243 & 1.0409 & 1.0363 & 1.0331 & 1.0308 \\
\hline
\end{tabular}

(b) For 30-bus system

\begin{tabular}{lccccc}
\hline \multirow{2}{*}{ Cases } & \multirow{2}{*}{ Preinsertion of FACTS } & \multicolumn{3}{c}{ Postinsertion of FACTS } \\
& & FA & SFLA & DE & 1.0288 \\
\hline Case 1 & 1.0260 & 1.0296 & 1.0306 & 0.9626 & 1.0265 \\
Case 2 & 0.9520 & 0.9961 & 0.9664 & 1.0298 & 0.9602 \\
Case 3 & 1.0109 & 1.0380 & 1.0108 & 1.0222 \\
\hline
\end{tabular}

The 30-bus system has 6 generator buses, 24 load buses, and 41 transmission lines. System data and results are based on $100 \mathrm{MVA}$ and bus number 1 is the reference bus. In order to verify the presented models and illustrate the impact of circuit element model of SSSC with variable susceptance model of SVC combination study, three different operating conditions are considered as mentioned below.

Case 1. The system with normal load in all the load buses is considered as normal condition and the Newton-Raphson load flow is carried out with loading factor value equal to 1 .

Case 2. The system with $50 \%$ increased load in all the load buses is considered as a critical condition. Loading of the system went beyond this level and results in poor voltage profile in the load buses and unacceptable real power loss level.

Case 3. Contingency is imposed by considering the most critical line outage in the system. This is the most suitable condition for voltage stability analysis of a power system as voltage stability is usually triggered by line outages.

Newton-Raphson program is repeatedly run with the absence and presence of FACTS device combination. The voltage stability limit improvement is assessed by the value of LQP index. The voltage stability index values of top five stressed lines under all cases with preinsertion and postinsertion of FACTS devices are shown in Table 2. It is evident from the table that LQP values of the stressed lines are reduced after placement of FACTS devices in the system.
For quick assessment of voltage stability limit improvement of the system under the three different operating conditions, sum of the LQP index values of all the lines before and after the insertion of FACTS devices combination is compared in Figure 6. The reduction in the index value through the proposed method indicates the best voltage stability limit improvement.

The line outage is ranked according to the severity and the severity is taken on the basis of the line quality proximity index values and such values are arranged in descending order. The maximum value of index indicates most critical line for outage. Line outage contingency screening and ranking are carried out on the test systems and the results are shown in Table 3.

It is clear from Table 3 that outage of lines numbers 1 and 5 are the most critical line outages of 14 - and 30-bus systems, respectively. This situation is considered for voltage stability improvement. Outage of other lines has not much impact on the system and therefore they are not given importance. Load flow is run on the system with the lines that have outages. Outage of these lines results in large real power loss and voltage profile reduction in most of the load buses. The system is under stressed conditions and needs to be relieved by some means. Installation of FACTS devices at suitable locations can relieve the system much from stressed conditions (reduced line losses).

FACTS devices help the system to maintain acceptable voltage profile in the load buses. Under normal operating conditions, most of the bus voltage magnitudes are within the normal value. During critical and contingency conditions, voltage magnitude of remote load buses are below 0.95 (lower 
TABLE 5: Minimum-maximum load bus voltage values in p.u.

(a) For 14-bus system

\begin{tabular}{|c|c|c|c|c|c|c|c|c|c|c|c|c|}
\hline \multirow{3}{*}{ Cases } & \multicolumn{6}{|c|}{$V_{\mathrm{MIN}}$} & \multicolumn{6}{|c|}{$V_{\text {MAX }}$} \\
\hline & \multirow{2}{*}{$\begin{array}{l}\text { Preinsertion } \\
\text { of FACTS }\end{array}$} & \multirow{2}{*}{ Bus number } & \multicolumn{4}{|c|}{ Postinsertion of FACTS } & \multirow{2}{*}{$\begin{array}{l}\text { Preinsertion } \\
\text { of FACTS }\end{array}$} & \multirow{2}{*}{ Bus number } & \multicolumn{4}{|c|}{ Postinsertion of FACTS } \\
\hline & & & FA & SFLA & $\mathrm{DE}$ & PSO & & & FA & SFLA & $\mathrm{DE}$ & PSO \\
\hline Case 1 & 1.0173 & 4 & 1.0252 & 1.0211 & 1.0203 & 1.0143 & 1.0604 & 7 & 1.0696 & 1.0673 & 1.0642 & 1.0617 \\
\hline Case 2 & 0.9656 & 14 & 1.0004 & 0.9884 & 0.9933 & 0.9824 & 1.0101 & 7 & 1.0211 & 1.0176 & 1.0199 & 1.0155 \\
\hline Case 3 & 0.9913 & 5 & 1.0264 & 1.0208 & 1.0104 & 1.0111 & 1.0350 & 13 & 1.0496 & 1.0490 & 1.0460 & 1.0438 \\
\hline
\end{tabular}

(b) For 30-bus system

\begin{tabular}{|c|c|c|c|c|c|c|c|c|c|c|c|c|}
\hline \multirow{3}{*}{ Cases } & \multicolumn{6}{|c|}{$V_{\mathrm{MIN}}$} & \multicolumn{6}{|c|}{$V_{\text {MAX }}$} \\
\hline & \multirow{2}{*}{$\begin{array}{l}\text { Preinsertion } \\
\text { of FACTS }\end{array}$} & \multirow{2}{*}{ Bus number } & \multicolumn{4}{|c|}{ Postinsertion of FACTS } & \multirow{2}{*}{$\begin{array}{l}\text { Preinsertion } \\
\text { of FACTS }\end{array}$} & \multirow{2}{*}{ Bus number } & \multicolumn{4}{|c|}{ Postinsertion of FACTS } \\
\hline & & & FA & SFLA & $\mathrm{DE}$ & PSO & & & FA & SFLA & $\mathrm{DE}$ & PSO \\
\hline Case 1 & 0.9953 & 30 & 0.9978 & 0.9976 & 0.9959 & 0.9954 & 1.0576 & 11 & 1.0820 & 1.0820 & 1.0820 & 1.0822 \\
\hline Case 2 & 0.8915 & 30 & 0.9662 & 0.9035 & 0.9415 & 0.9410 & 1.0004 & 11 & 1.0667 & 1.0620 & 1.0520 & 1.0550 \\
\hline Case 3 & 0.9661 & 5 & 1.0121 & 0.9600 & 0.9600 & 0.9607 & 1.0495 & 11 & 1.0820 & 1.0820 & 1.0820 & 1.0820 \\
\hline
\end{tabular}

TABLE 6: Real power loss values comparison (in MW).

(a) For 14-bus system

\begin{tabular}{lccccc}
\hline \multirow{2}{*}{ Conditions } & \multirow{2}{*}{ Preinsertion of FACTS (initial) } & \multicolumn{3}{c}{ Postinsertion of FACTS } \\
& & FA & SFLA & DE & 11.693 \\
Case 1 & 13.401 & 11.014 & 11.409 & 28.106 \\
Case 2 & 35.042 & 28.018 & 28.991 & 28.875 & 29.019 \\
Case 3 & 24.183 & 18.046 & 19.255 & 19.389 & 19.771 \\
\hline
\end{tabular}

(b) For 30-bus system

\begin{tabular}{lccccc}
\hline \multirow{2}{*}{ Conditions } & \multirow{2}{*}{ Preinsertion of FACTS (Initial) } & \multicolumn{3}{c}{ Postinsertion of FACTS } \\
& & FA & SFLA & DE & PSO \\
\hline Case 1 & 17.514 & 13.467 & 14.852 & 16.157 & 16.504 \\
Case 2 & 46.900 & 40.990 & 45.797 & 41.258 & 43.272 \\
Case 3 & 32.569 & 22.801 & 29.272 & 23.234 & 25.561 \\
\hline
\end{tabular}

bound of allowable value). These bus voltages are improved after the FACTS devices are installed. Voltage profile value comparison under all cases incorporating the series-shunt FACTS devices combination is depicted separately in Figures 7 (a) and 7(b) under both test cases. It is obvious from the figure that voltage profile comparison of the system is improved better with the proposed method incorporating FACTS devices combination. The comparison of average value of load bus voltage also proves the enhancing behavior of voltage stability limit incorporating with FACTS devices of all cases shown in Table 4. Table 5 exposes the comparison of minimum and maximum load bus voltages in both the absence and presence of FACTS devices under all cases.

In real power loss minimization point of view through insertion of FACTS devices, the real power loss under Case 1 is decreased by 2.387 and $4.047 \mathrm{MW}$, respectively, for 14 - and 30-bus systems. In Case 2, the reduction in real power loss rate is 7.024 and $5.910 \mathrm{MW}$, respectively. The reduction rate in real power loss is 6.137 and $9.768 \mathrm{MW}$, respectively, under Case 3 operation. The real power loss values of proposed method compared with other important evolutionary techniques under all cases are shown in Table 6.

The percentage of reduction in real power loss comparison under all cases including both combinations is depicted in Figure 8. Obviously from the results shown in Table 6, the proposed method is more efficient than other evolutionary techniques given here to reduce the real power loss minimization application. The much reduction in real power loss and increase in voltage magnitudes after the insertion of FACTS devices are highly efficient in relieving a power network from stressed condition and improving voltage stability limit. The most suitable size and location of combinations of FACTS devices to improve the voltage stability limit and real power loss minimization are also given in Table 7 under all cases with 14- and 30-bus systems, respectively. The optimized size of SVC inserted with both combinations is not in larger value which helps to reduce in cost. 
TABLE 7: Best location and size of FACTS devices.

(a) For 14-bus system

\begin{tabular}{|c|c|c|c|c|c|}
\hline \multicolumn{2}{|c|}{ Cases } & \multicolumn{2}{|c|}{ Series } & \multicolumn{2}{|l|}{ Shunt } \\
\hline & & Location (line number) & Size (degrees of compensation) & Location (bus number) & Size (MVar) \\
\hline \multirow{4}{*}{ Case 1} & FA & 10 & $0.0722+j 0.1464$ & 5 & 7.2015 \\
\hline & SFLA & 4 & $0.0377+j 0.0916$ & 12 & 8.6554 \\
\hline & $\mathrm{DE}$ & 15 & $0.0461+j 0.1540$ & 10 & 6.9988 \\
\hline & PSO & 3 & $0.0622+j 0.1067$ & 12 & 8.3037 \\
\hline \multirow{4}{*}{ Case 2} & FA & 12 & $0.0823+j 0.0961$ & 13 & 11.211 \\
\hline & SFLA & 1 & $0.0536+j 0.1642$ & 11 & 10.6217 \\
\hline & $\mathrm{DE}$ & 9 & $0.0507+j 0.1145$ & 12 & 9.9654 \\
\hline & PSO & 11 & $0.0727+j 0.0836$ & 10 & 7.2510 \\
\hline \multirow{4}{*}{ Case 3} & FA & 12 & $0.0769+j 0.0810$ & 13 & 9.6817 \\
\hline & SFLA & 10 & $0.0421+j 0.1162$ & 5 & 10.6528 \\
\hline & $\mathrm{DE}$ & 2 & $0.0489+j 0.0773$ & 11 & 8.9207 \\
\hline & PSO & 7 & $0.0673+j 0.1286$ & 10 & 11.4368 \\
\hline
\end{tabular}

(b) For 30-bus system

\begin{tabular}{|c|c|c|c|c|c|}
\hline \multirow{2}{*}{\multicolumn{2}{|c|}{ Cases }} & \multicolumn{2}{|c|}{ Series } & \multicolumn{2}{|l|}{ Shunt } \\
\hline & & Location (line number) & Size (degrees of compensation) & Location (bus number) & Size (MVar) \\
\hline \multirow{4}{*}{ Case 1} & FA & 5 & $0.0159+j 0.0924$ & 12 & 8.6962 \\
\hline & SFLA & 1 & $0.0086+j 0.0833$ & 19 & 6.9688 \\
\hline & $\mathrm{DE}$ & 6 & $0.0239+j 0.2664$ & 20 & 5.8131 \\
\hline & PSO & 12 & $0.0191+j 0.0977$ & 23 & 15.0806 \\
\hline \multirow{4}{*}{ Case 2} & FA & 6 & $0.0137+j 0.0384$ & 17 & 9.0607 \\
\hline & SFLA & 9 & $0.0170+j 0.1243$ & 21 & 14.1058 \\
\hline & $\mathrm{DE}$ & 5 & $0.0289+j 0.0931$ & 30 & 6.2554 \\
\hline & PSO & 8 & $0.0281+j 0.0447$ & 18 & 19.0106 \\
\hline \multirow{4}{*}{ Case 3} & FA & 11 & $0.0311+j 0.1417$ & 26 & 8.0115 \\
\hline & SFLA & 9 & $0.0115+j 0.1302$ & 28 & 6.7499 \\
\hline & $\mathrm{DE}$ & 6 & $0.0112+j 0.0478$ & 25 & 5.8559 \\
\hline & $\mathrm{PSO}$ & 8 & $0.0291+j 0.1189$ & 3 & 18.2640 \\
\hline
\end{tabular}

\section{Conclusion}

In this paper, optimal location and size of series-shunt FACTS devices for voltage stability limit improvement and loss minimization through firefly algorithm are demonstrated. The voltage stability limit improvement and real power loss minimization are done under three operating cases such as normal, critical loading, and line outage contingency conditions. The LQP index is used for voltage stability assessment. The circuit element model of SSSC is considered to improve the voltage stability limit by controlling power flows and maintaining voltage profile. This model is easy to incorporate the effect of SSSC into NewtonRaphson load flow program coding. The variable susceptance model of SVC is used in a combined manner with SSSC. It is clear from the numerical results that voltage stability limit improvement and real power loss minimization are highly encouraging. The real power loss minimization and voltage stability limit improvement is remarkable by the combined action of power flow control of SSSC and reactive power compensation by SVC through firefly algorithm over other evolutionary optimization techniques given in this paper.

\section{Conflict of Interests}

The authors declare that there is no conflict of interests regarding the publication of this paper.

\section{References}

[1] T. V. Cutsem and C. Vournas, Voltage Stability of Electric Power Systems, Kluwer Academic, New York, NY, USA, 1998.

[2] P. Kundur, Power System Stability and Control, McGraw-Hill, New York, NY, USA, 1994.

[3] C. W. Taylor, Power System Voltage Stability, McGraw-Hill, New York, NY, USA, 1994.

[4] T. van Cutsem, "Voltage instability: phenomena, countermeasures, and analysis methods," Proceedings of the IEEE, vol. 88, no. 2, pp. 208-227, 2000.

[5] P. Kessel and H. Glavitsch, "Estimating the voltage stability of power system," IEEE Transactions on Power Delivery, vol. 1, no. 3, pp. 346-354, 1986.

[6] H. J. Wan, J. D. McCalley, and V. Vittal, "Risk based voltage security assessment," IEEE Transactions on Power Systems, vol. 15, no. 4, pp. 1247-1254, 2000. 
[7] I. Dobson and H.-D. Chiang, "Towards a theory of voltage collapse in electric power systems," Systems and Control Letters, vol. 13, no. 3, pp. 253-262, 1989.

[8] "Technical Analysis of the August 14, 2003, Blackout: What Happened, Why, and What Did We Learn?" A report by the North American Electrical Reliability Council Steering Group, New Jersey, July 2004.

[9] N. G. Hingorani and L. Gyugyi, Understanding FACTS: Concepts and Technology of Flexible AC Transmission Systems, IEEE Press, 2000.

[10] K. K. Sen and M. L. Sen, Introduction to FACTS Controllers Theory, Modeling, and Applications, IEEE Press, 2009.

[11] G. Wu, A. Okoyama, J. He, and Y. Yu, "Allocation and control of FACTS devices for steady state stability enhancement of large scale power system," International Conference on Power System Technology, vol. 1, pp. 357-361, 1998.

[12] N. Yorino, E. E. El-Araby, H. Sasaki, and S. Harada, "A new formulation for FACTS allocation for security enhancement against voltage collapse," IEEE Transactions on Power Systems, vol. 18, no. 1, pp. 3-10, 2003.

[13] S. Biansoongnern, S. Chusanapiputt, and S. Phoomvuthisarn, "Optimal SVC and TCSC placement for minimization of transmission losses," in Proceedings of the International Conference on Power System Technology, pp. 1-5, October 2006.

[14] M. A. Abido, "Power system stability enhancement using FACTS controllers: a review," The Arabian Journal For Science and Engineering, vol. 34, no. 1, pp. 153-172, 2009.

[15] O. L. Bekri, "Optimal location of SVC and TCSC for voltage stability enhancement," in Proceedings of the 4th International Power Engineering and Optimization Conference (PEOCO '10), pp. 7-12, June 2010.

[16] Y. Zhang and Y. Zhang, "A novel power injection model of embedded SSSC with multi-control modes for power flow analysis inclusive of practical constraints," Electric Power Systems Research, vol. 76, no. 5, pp. 374-381, 2006.

[17] A. Sode-Yome, N. Mithulananthan, and K. Y. Lee, "Static voltage stability margin enhancement using STATCOM, TCSC and SSSC" in Proceedings of the IEEE/PES Transmission and Distribution Conference and Exhibition, pp. 1-6, August 2005.

[18] C. A. Canizares and Z. T. Faur, "Analysis of SVC and TCSC controllers in voltage collapse," IEEE Transactions on Power Systems, vol. 14, no. 1, pp. 158-165, 1999.

[19] S. Musunuri and G. Dehnavi, "Comparison of STAT COM, SVC, TCSC, and SSSC performance in steady state voltage stability improvement," in Proceedings of the North American Power Symposium (NAPS '10), pp. 1-7, September 2010.

[20] P. Kundur, K. Morison, and B. Gao, "Practical considerations in voltage stability assessment," International Journal of Electrical Power and Energy Systems, vol. 15, no. 4, pp. 205-215, 1993.

[21] V. Ajjarapu, Computational Techniques for Voltage Stability Assessment and Control, Springer Science, 2006.

[22] S. Fliscounakis, P. Panciatici, F. Capitanescu, and L. Wehenkel, "Contingency ranking with respect to overloads in large power systems taking into account uncertainity, preventive and corrective actions," IEEE Transactions on Power Systems, vol. 28, no. 4, pp. 4909-4917, 2013.

[23] A. Y. Abdelaziz, A. T. M. Taha, M. A. Mostafa, and A. M. Hassan, "Power systen contingency ranking using fuzzy logic based approach," International Journal of Intelligent Systems and Applications, no. 2, pp. 24-28, 2013.

[24] P. S. Venkataramu and T. Ananthapadmanabha, "Installation of unified power flow controller for voltage stability margin enhancement under line outage contingencies," Iranian Journal of Electrical and Computer Engineering, vol. 5, no. 2, pp. 90-96, 2006.

[25] M. Ja'fari and S. Afsharnia, "Voltage stability enhancement in contingency conditions using shunt FACTS devices," in Proceedings of the EUROCON: The International Conference on Computer as a Tool, pp. 1660-1665, September 2007.

[26] P.-A. Loef, G. Andersson, and D. J. Hill, "Voltage stability indices for stressed power systems," IEEE Transactions on Power Systems, vol. 8, no. 1, pp. 326-335, 1993.

[27] M. Moghavvemi and F. M. Omar, "Technique for contingency monitoring and voltage collapse prediction," IEE Proceedings on Generation, Transmission and Distribution, vol. 145, no. 6, pp. 634-640, 1998.

[28] M. Moghavvemi and O. Faruque, "Real time contingency evaluation and ranking technique," IEE Proceedings on Generation, Transmission and Distribution, vol. 145, no. 5, pp. 517-524, 1998.

[29] I. Musirin and T. K. A. Rahman, "Novel fast voltage stability index (FVSI) for voltage stability analysis in power transmission system," in Proceedings of the Student Conference on Research and Development Proceedings, pp. 265-268, 2002.

[30] C. Reis, A. Andrade, and F. P. Maciel, "Line stability indices for voltage collapse prediction," in Proceedings of the 2nd IEEE International Conference on Power Engineering, Energy and Electrical Drives, pp. 239-243, March 2009.

[31] X. S. Yang, Nature-Inspired Metaheuristic Algorithms, Luniver Press, 2008.

[32] X. S. Yang, "Firefly algorithms for multimodal optimization," in Stochastic Algorithms: Foundations and Applications, SAGA, vol. 5792 of Lecture Notes in Computer Sciences, pp. 169-178, 2009.

[33] S. Łukasik and S. Żak, "Firefly algorithm for continuous constrained optimization task, computational collective intelligence," in Semantic Web, Social Networks and Multi-Agent Systems, vol. 5796 of Lecture Notes in Computer Science, pp. 97106, 2009.

[34] N. D. Reppen, R. R. Austria, J. A. Uhrin, M. C. Patel, and A. Galatic, "Performance of methods for ranking a evaluation of voltage collapse contingencies applied to a large-scale network," in Proceedings of the IEEE Joint International Conference, pp. 337-343, 1993.

[35] G. C. Ejebe, G. D. Irisarri, S. Mokhtari, O. Obadina, P. Ristanovic, and J. Tong, "Methods for contingency screening and ranking for voltage stability analysis of power systems," in Proceedings of the IEEE Power Industry Computer Application Conference, pp. 249-255, May 1995.

[36] E. Vaahedi, C. Fuchs, W. Xu et al., "Voltage stability contingency screening and ranking," IEEE Transactions on Power Systems, vol. 14, no. 1, pp. 256-265, 1999. 

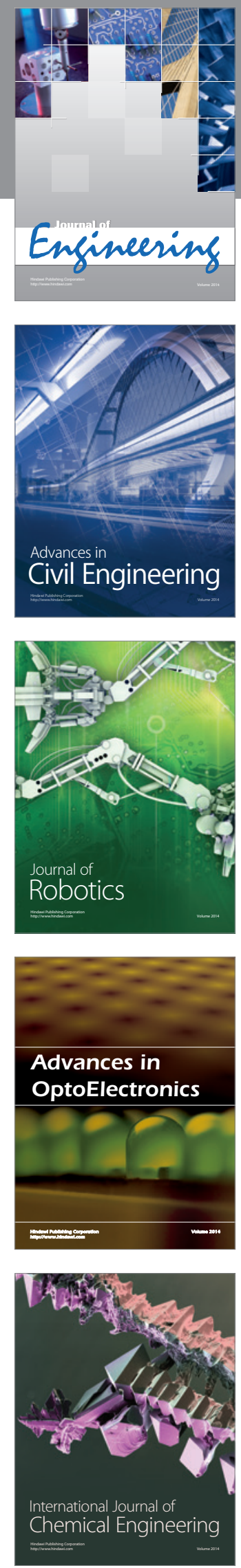

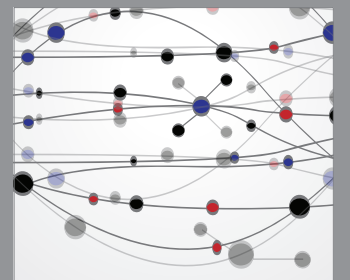

The Scientific World Journal
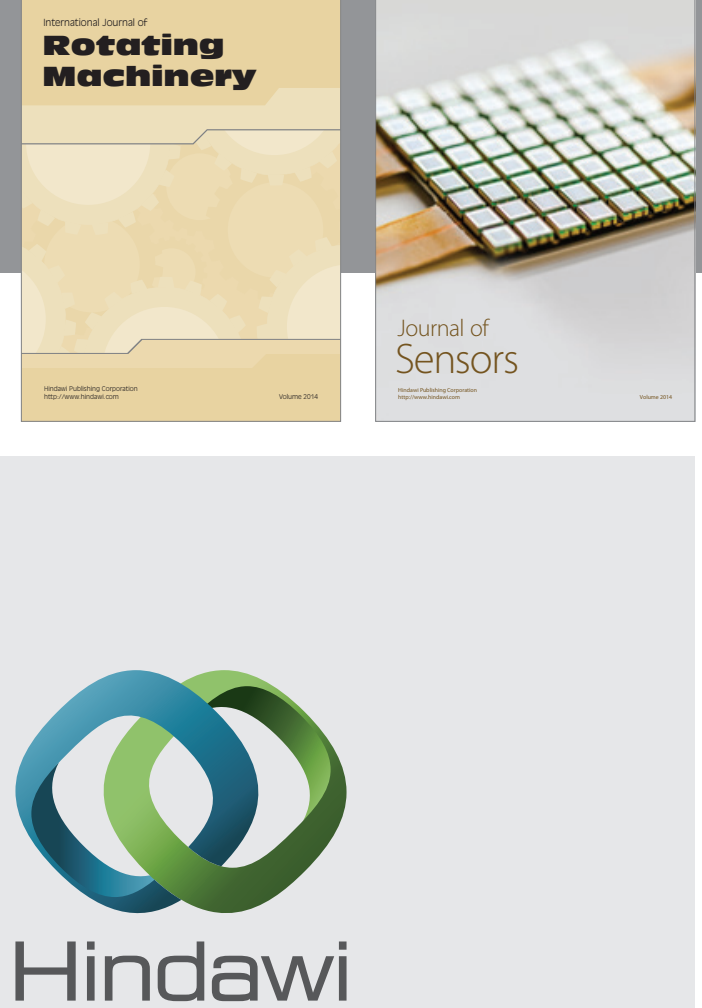

Submit your manuscripts at http://www.hindawi.com
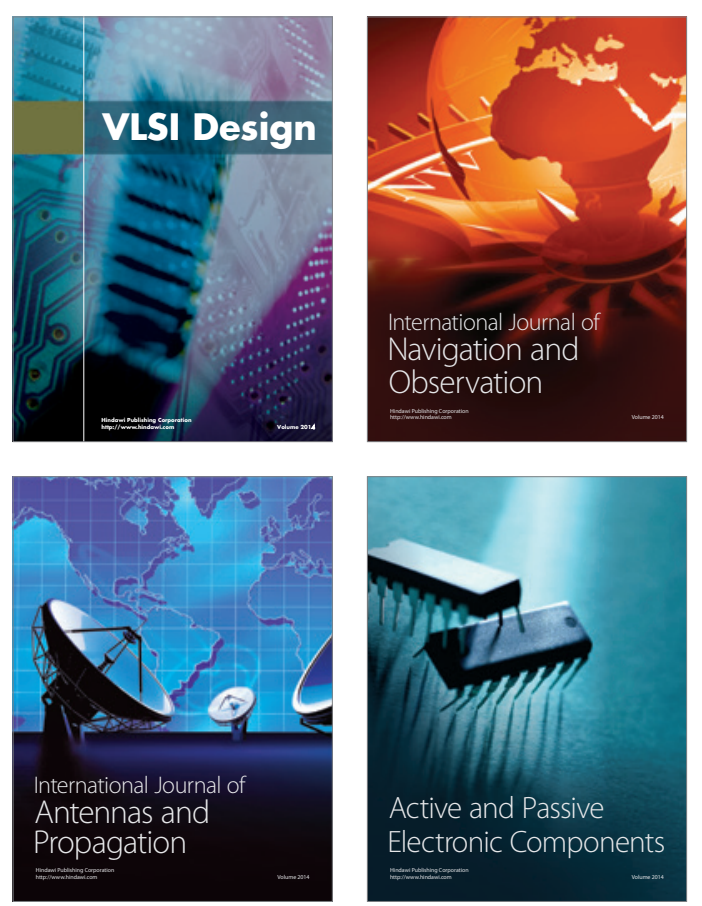
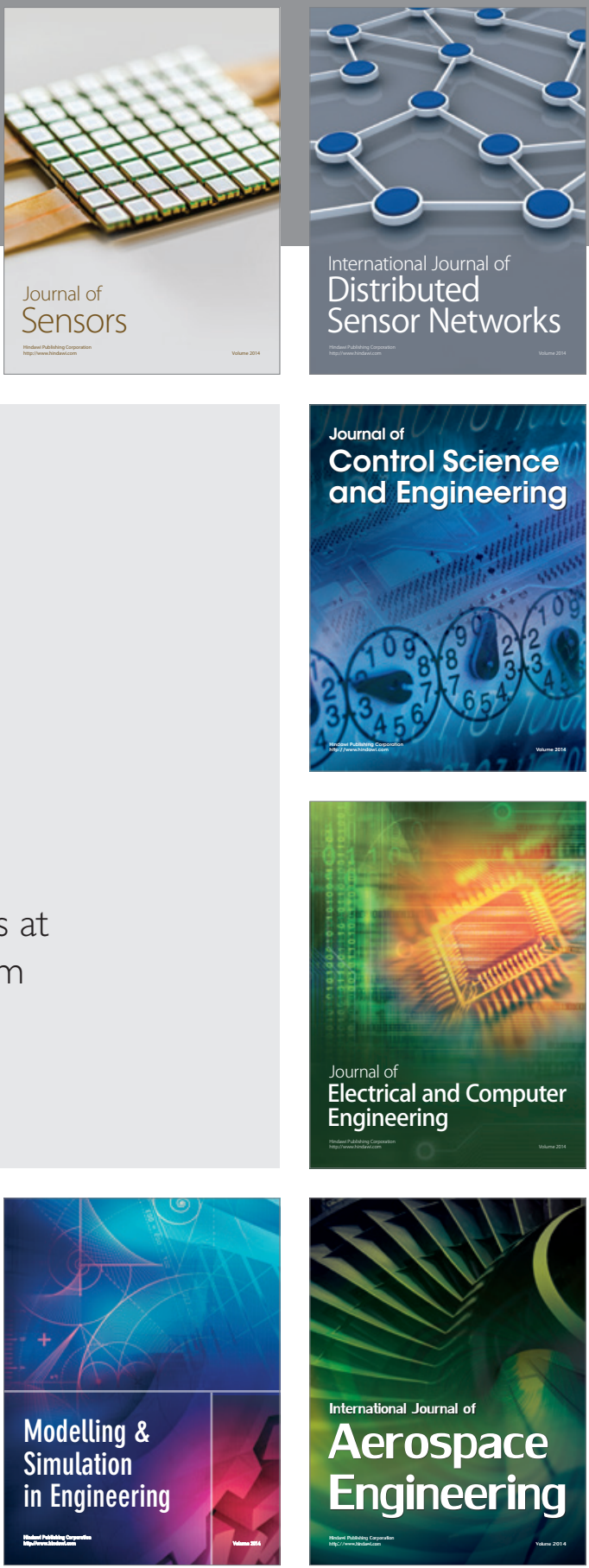

Journal of

Control Science

and Engineering
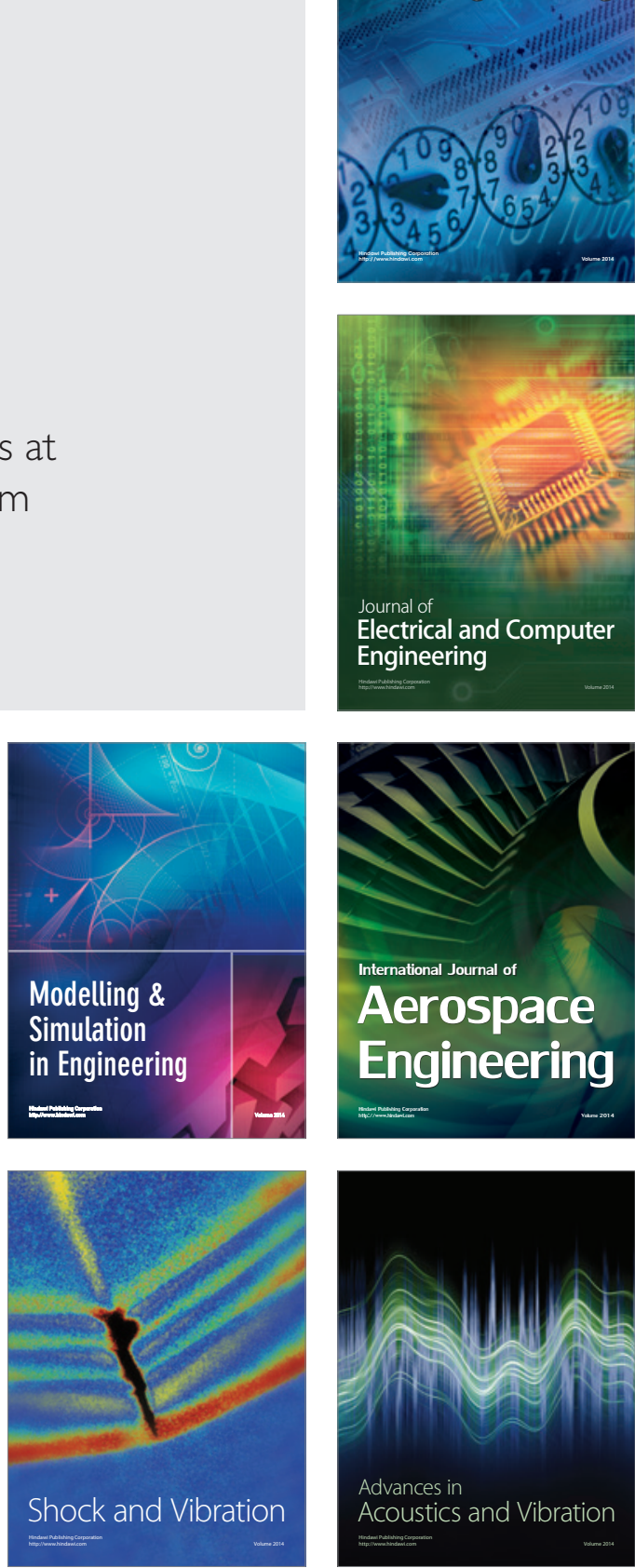